\title{
COMPARISON AND ANALYSIS OF THE ACCURACY OF GEE PLATFORM PIXEL-BASED SUPERVISED CLASSIFICATION-TAKING SHANDONG PROVINCE AS AN EXAMPLE
}

\author{
C. L. Jia ${ }^{1, *}$ J. Chen ${ }^{2}, \mathrm{H} . \mathrm{Wu}^{2}$ \\ 1 China University of Mining and Technology, School of Environment Science and Spatial Informatics, Xuzhou, China - \\ reggaj@qq.com
}

2 National Geomatics Center of China, Beijing, China - chenjun@ngcc.cn, wuhao@ngcc.cn

\author{
Commission IV, ICWG IV/III, WG IV/4
}

KEY WORDS: Landcover; GEE; PBSC; Shandong; Landsat; GlobeLand30

\begin{abstract}
:
Remote sensing is going through a basic transformation, in which a wide array of data-rich applications is gradually taking the place of methods interpreting one or two imageries. These applications have been greatly facilitated by Google Earth Engine (GEE), which provides both imagery access and a platform for advanced analysis techniques. Within the field of land cover classification, GEE provides the ability to create fast new classifications, particularly at global extents. Despite the role of indices and other ancillary data in classification, GEE platform pixel-based supervised classification (GEE-PBSC), as a relatively fast and common classification method in remote sensing, was not directly analysed and assessed about accuracy in current researches. We ask how high the classification accuracy of GEE-PBSC is, and which type of land cover is more suitable to be classified by GEE-PBSC method with a credible accuracy. Here we adopt GEE-PBSC method to classify Landsat 5 TM imageries in Shandong province in 2010, and compare the result with GlobeLand30 product in 2010 from three aspects: type composition, type confusion and spatial consistency to assess the classification accuracy. Before the comparison, multiple cross-validation, which shows that the overall average test accuracy is about $74 \%$, is required to ensure the reliability. The comparison experiment shows that the spatial consistency ratio of artificial surface, cultivated land and water is about $99.30 \%, 85.78 \%$ and $73.02 \%$ respectively. The pixel purity of artificial surface and cultivated land is about $90.26 \%$ and $81.45 \%$ respectively. The overall spatial consistency ratio is about $82.04 \%$. Although the GEE-PBSC method can achieve high test accuracy, the result is still far from GlobeLand30 product in 2010. Because the GEE-PBSC only uses the pixel information of imageries and does not integrate other multi-source data to assist classification. In addition, classification result also shows that using GEE-PBSC to classify artificial surface and cropland has obvious advantages over other land classes, and their classification results is close to GlobeLand30.
\end{abstract}

Corresponding author 


\section{INTRODUCTION}

Land cover refers to the material synthesis with different natural properties and characteristics on the earth's surface, which represents the differences in surface hydrothermal and material balance, biogeochemical circulation and other processes. Its spatial distribution and changes also reflect the interaction process between nature and humans to a certain extent (Turner et al., 1993). Land cover change alters the land-atmosphere moisture, energy and carbon cycle, contributing to global climate change (Foley et al., 2005). For example, the change of land cover will significantly change the characteristics such as surface albedo and emissivity, so as to affect the surface hydrothermal process budget and generate strong feedback on the climate system (Weng et al., 2007). Deforestation and other land cover changes are also a major source of increased greenhouse gas $\left(\mathrm{CO}_{2}\right)$ concentrations (Stocker, 2014). In addition, changes in land cover can directly affect the stability and diversity of ecosystems (Naidoo et al., 2008). Information on land cover and its changes has been recognized as an indispensable and important basic data in the research fields of global environmental change, geographical country (world) situation monitoring, sustainable development planning and land resource management (Feddema et al., 2005; Xian, Crane, 2006; Reid et al., 2010; Pereira et al., 2013). For example, The intergovernmental Group on Earth Observation (GEO) lists land cover as one of the key parameters for the study of surface processes (Zell et al., 2012). Therefore, a scientific and accurate measurement of the spatial distribution and dynamic change of global land cover is of great significance for the study of energy balance, carbon cycle and other biogeochemical cycles, climate change and biodiversity of the earth system.

With petabyte-scale archives of remote sensing data available for free, a new era in remote sensing has been launched, characterized by free data and multi-temporal analysis methods for tracking land cover change (Coppin, Bauer, 1996; Verbesselt, 2012; Wulder et al., 2012; Zhu, 2017; Wulder et al., 2018; Sidhu et al., 2018). There are now many potential sources of satellite-based imagery spanning more than 40 years (Woodcock et al., 2008; Wulder et al., 2012). Landsat is the longest running time series, but additional sensors also provide free imageries (Yüksel et al., 2008; Giri et al., 2013). In recent years, sentinel-2 satellites launched in 2015 and 2017 have higher spatial resolution and return visit time (Drusch et al., 2012; Li, Roy, 2017). The increase in fine resolution and temporal data adds to the potential benefits of algorithms that incorporate evidence form a large number of satellite imageries into useful maps that monitor changes in the landscape.

Unfortunately, taking full advantage of these resources still requires considerable technical expertise and effort. These requirements are meted by GEE, which is a cloud-based platform that make it easy to access high-performance computing resources for processing very large geospatial datasets (Gorelick et al., 2017). GEE integrates multi-source and multi-scale remote sensing data from MODIS, Landsat TM/OLI and other remote sensing data around the world. With the powerful computing power of cloud platform, many researches based on GEE were carried out in recent years, including: Vegetation Mapping and Monitoring (Robinson et al., 2017; Goldblatt et al., 2017; Tsai et al., 2018), Land cover Mapping (Lee et al., 2018; Mahdianpari et al., 2018; Tsai et al., 2018), agricultural applications (Xiong et al., 2017; He et al., 2018) and disaster management and earth science (Sproles et al., 2018; Liu et al., 2018)

However, GEE-PBSC, as a relatively fast and common classification method in remote sensing, is only one step of the above works. There is no literature that directly analyses and evaluates the information classification ability of GEE-PBSC Therefore, this paper takes the classification of land cover information of Shandong province as an example, and through the accuracy analysis of GEE platform classification result acquired by applying GEE-PBSC, determines the land cover type suitable for classification, and provides certain references and suggestions for the use of platform's land cover mapping.

\section{METHODS}

\subsection{Study Area}

Located on the eastern coast of China, Shandong Province is located in the lower reaches of the Yellow River, between $114^{\circ}$ $36^{\prime} \mathrm{E} \sim 122^{\circ} 43^{\prime} \mathrm{E}, 34^{\circ} 25^{\prime} \mathrm{N} \sim 38^{\circ} 23^{\prime} \mathrm{N}$, with a total land area of $1.571 \times 10^{7} \mathrm{hm}^{2}$. In the middle of the terrain, the mountains are prosperous, the eastern hills are undulating and gentle, and the west and the north are low and flat. Plain basins, mountainous hills and waters account for $63 \%, 34 \%$ and $3 \%$ of 
the total land area, respectively. The study area has a mix of grasslands, forest, water and artificial surface and extensive agricultural areas. The variety of land cover types and less complex terrain make this area a good location to test the classification accuracy of GEE-PBSC.

\subsection{Land Cover Categories}

For this study, in order to ensure the comparability of classification results, the definitions of land cover type refer to the classification results of GlobeLand30 in Shandong province in 2010. We identify seven fundamental land cover categories: Cropland; Forest; Grassland; Wetland; Water; Artificial surface and Bare land. Referring to Sentinel high-resolution imagery and GlobeLand30 data products, 835 sample points are selected through manual interpretation, among which $60 \%$ are the training samples and the rest are the test samples for subsequent calls of GEE. The distribution of sample points and the statistics of various categories are shown in figure 1 and table 1 respectively.

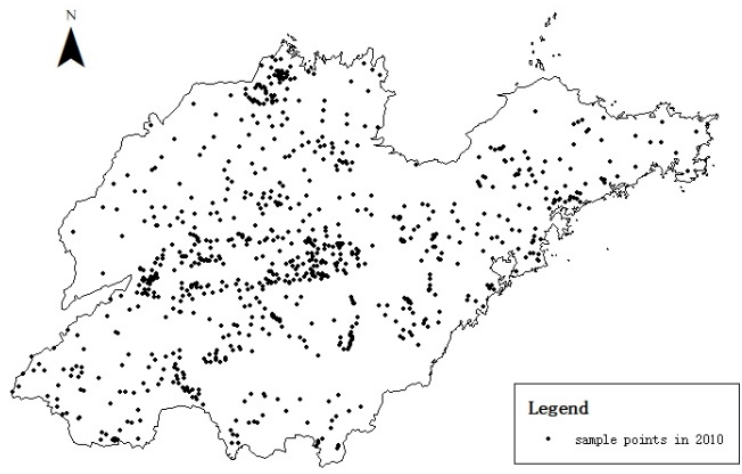

Figure 1. The distribution map of sample points in 2010

Table 1. The statistics of sample points

\begin{tabular}{lll}
\hline code & categories & number \\
\hline 0 & cropland & 216 \\
1 & forest & 149 \\
2 & grassland & 86 \\
3 & wetland & 59 \\
4 & water & 117 \\
5 & artificial surface & 157 \\
6 & shrubland & 51 \\
Total & & 835 \\
\hline
\end{tabular}

\subsection{Classification and Validation}

\subsubsection{Random Forest Classifier}

Random forest (RS) algorithm is an ensemble learning algorithm proposed by Breiman in 2001 (Beriman, 2001). It is an ensemble of classification trees, which are used to train and predict the samples with multiple trees, and the final classification result is decided by the vote of multiple tree classifiers. First, $\mathrm{N}$ training sets are classified from the original data set by bootstrap sampling technology, and the size of each training set is about $2 / 3$ of the original data set. Then, classification trees are established for each training set to generate a forest composed of $\mathrm{N}$ classification trees. During the growth process of each tree, $m$ attributes $(m \leqslant M)$ are randomly selected from all $\mathrm{M}$ characteristic variables, and the optimal attribute is selected for internal node branch according to the Gini coefficient minimum principle among these $\mathrm{M}$ attributes. Finally, the prediction results of $\mathrm{N}$ classification trees are set, and the category of new samples is determined by voting. About 1/3 of the data in each sampling was not selected, and the OOB error was generated by using the out-of-bag data to estimate the internal error.

\subsubsection{Spatial consistency validation method}

Type confusion analysis. It can give the degree of confusion between two sets of products and the same type, and assess the similarity of the area composition of the two sets of products. By using the spatial overlay method, the spatial correspondence relation of two sets of products pixel by pixel is obtained. When the local type is consistent, the local type is regarded as pure; otherwise, the local type is regarded as confused. Firstly, one set of products is determined as the reference data and the other set as the evaluation data, and the type purity $\mathrm{A}_{i}$ of two sets of products with different land types is defined, as shown in equation (1):

$$
A_{i}=\frac{N_{i}}{M_{i}} \times 100 \%
$$

where $\quad M_{i}=$ pixel number of the $i$ th category in the reference data

$N_{i}=$ pixel number of the $i$ th category in the same position as $M_{i}$ in the evaluation data.

Spatial consistency analysis. Type confusion analysis is based on statistical results, which is not intuitive, while spatial 
consistency analysis can directionally analyse the spatial correspondence between different products pixel by pixel. The spatial consistency ratio $B_{i}$ of two different products land cover categories and the overall space consistency ratio $C_{i}$ of two sets of products are defined, as shown in equations (2) and (3):

$$
\begin{aligned}
& B_{i}=\frac{Z_{i}}{\left(X_{i}+Y_{i}\right) / 2} \times 100 \% \\
& C_{i}=\frac{\sum_{1}^{k} Z_{i}}{S} \times 100 \%
\end{aligned}
$$

where $X_{i}, Y_{i}=$ pixel numbers of the $i$ th category in our product $\mathrm{X}$ and product $\mathrm{Y}$ respectively

$Z_{i}=$ pixel number of the $i$ th category of two products in the same position

$k=$ the number of different land cover categories

$S=$ the total pixel number of any one of two sets of products under the same spatial range and resolution.

\section{RESULTS}

By applying RS algorithm, we classify Landsat 5 TM imageries data in Shandong province in 2010.

\subsection{Cross-validation}

In order to minimize the impact of training sample differences on classification accuracy, $60 \%$ of the samples are randomly selected each time as the training set, and the remaining $40 \%$ as the test set for 10 times of cross-validation experiments. The result shows that the overall average test accuracy is about $74 \%$.

\subsection{Spatial consistency experiment}

We analyse the classified product with the highest test accuracy (Figure 2) with GlobeLand30 product in 2010 (Figure 3) from three aspects: type composition, type confusion and spatial consistency, so as to evaluate the classification accuracy of GEE platform.

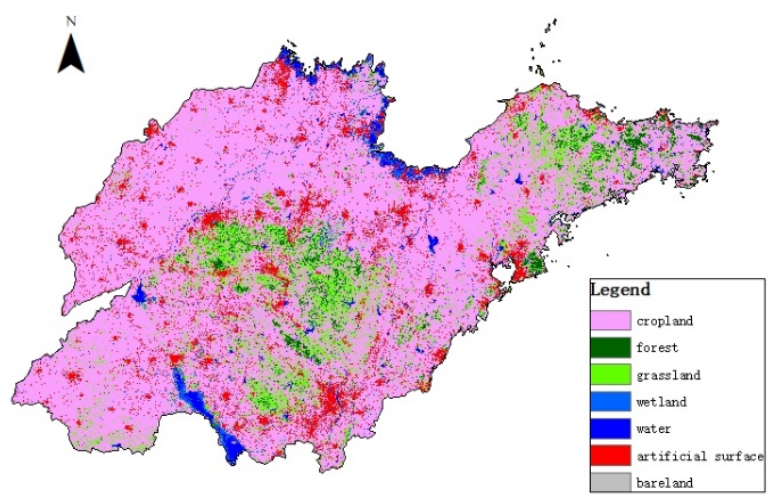

Figure 2. Our classified product with highest test accuracy in Shandong in 2010

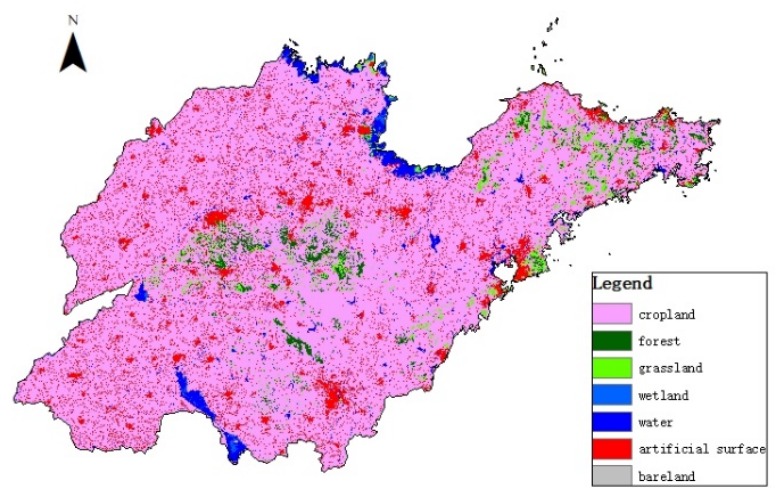

Figure 3. The GlobeLand30-2010 product in Shandong

\subsubsection{Type composition analysis}

The area ratio of each land cover type of the two sets products is calculated (Figure 4). The result shows that except for the underestimation of $8.05 \%$ of cultivated land area and overestimation of $7.84 \%$ of grassland area, the difference in the proportion of other land types is within $3 \%$, and the proportion is roughly the same.

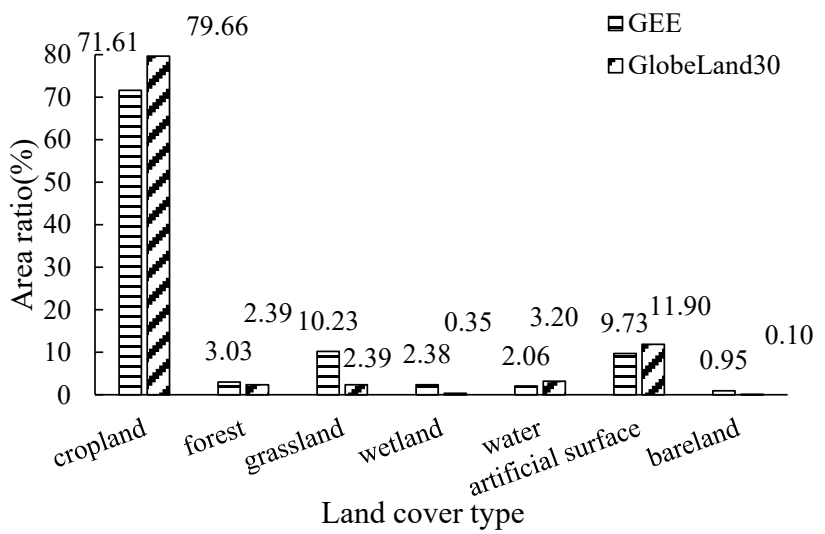

Figure 4. Area ratio of land cover types 


\subsubsection{Type confusion analysis}

The pixel and pixel corresponding relationship of our classified product and GlobeLand30-2010 product is obtained by overlaying them in ArcMap. Then we calculate the land cover type confused degree by using equation (1), where $\mathrm{M}=$ GlobeLand30 product, $\mathrm{N}=$ Our classified product, as shown in figure 5. The results show that the degree of land cover type confusions of artificial land, cultivated land, grassland, forest and water are relatively low (i.e. high purity), and the pixel purity is about $90.26 \%, 81.45 \%, 67.10 \%, 62.76 \%$ and $60.04 \%$, respectively. The purity of wetland and bare land is lower than $50 \%$ ( $40.43 \%$ and $18.84 \%$ respectively). It can also be shown from the figure that the mixture of forest and grassland, wetland and water is relatively obvious. Besides water bodies, a large proportion of artificial surface is also mixed in the wetland. In addition, bare land and other types of mixed is also serious.

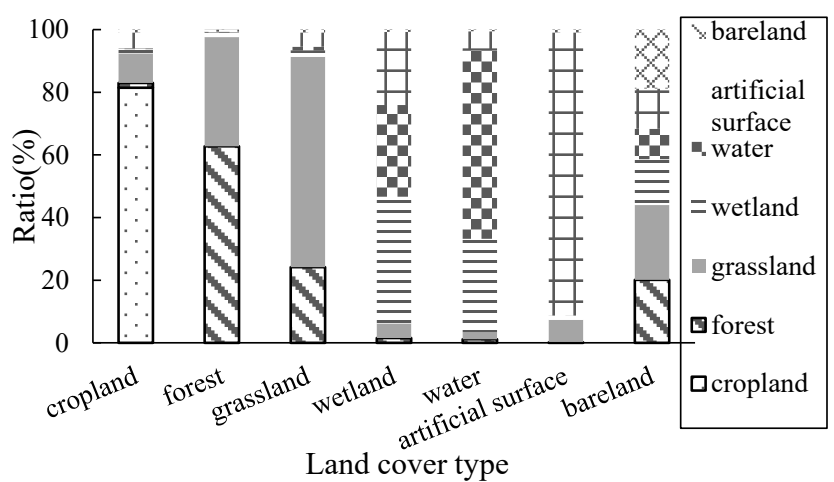

Figure 5. The confused degree of land cover types between our classification and GlobeLand30-2010 products (The abscissa in the figure represents the land cover type of globeland30-2010, and the ordinate represents the percentage of pixels in our classified product in a certain land cover type of globeland30-2010. When the abscissa is consistent with the land type of the ordinate, the land cover type is regarded as pure; otherwise, the ground type is regarded as confused).

\subsubsection{Spatial consistency analysis}

Spatial consistency ratio of land cover types (Figure 6) is calculated by using equation (2). As it can be shown from the figure that cultivated land and water was higher $(99.30 \%, 85.78 \%$ and $73.02 \%$, respectively), while that of forest, grassland, wetland and bare land was lower $(55.34 \%, 25.45 \%, 10.46 \%$ and $3.72 \%$, respectively).

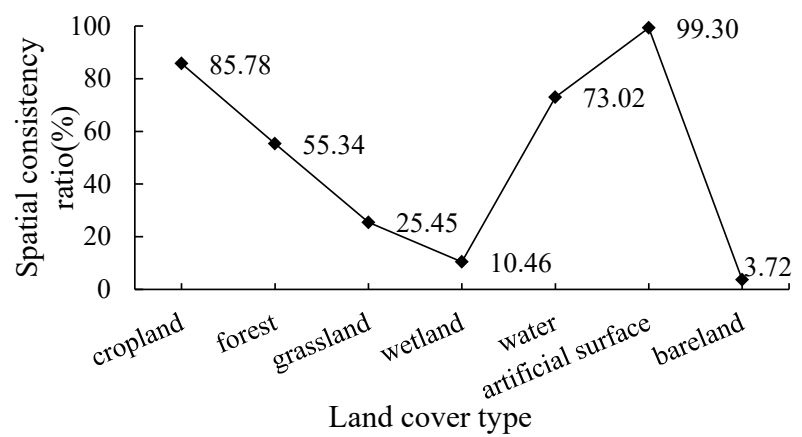

Figure 6. Spatial consistency ratio of land cover types

According to equation (3), $k=7$. Since the spatial range and resolution of the two sets of products are the same, $\mathrm{S}$ is the total pixel number of any one of our classified products and GlobeLand30-2010 products. The calculated result shows that the overall spatial consistency ratio between our classified products and GlobeLand30-2010 product is about $82.04 \%$, high consistency.

\section{DISCUSSION}

After the above comparative analysis, the following speculations can be made :(1) the GEE-PBSC method can be used to classify the artificial ground surface from the remote sensing images easily, because the classified results have higher spatial consistency with GlobeLand30 and higher pixel purity; (2) the results overestimated the area of cropland, but it still have good purity and good spatial consistency, which indicates GEE-PBSC method is a friendly to the classification of cropland; (3) although the classification results of water bodies are in good spatial consistency with GlobeLand30, water bodies and wetlands are badly mixed, and it is difficult to distinguish water bodies and wetlands from remote sensing images only by pixel information; (4) the mixture of forest and grassland is relatively obvious, and the spatial consistency of the results with GlobeLand30 is also low, indicating that it was not easy to distinguish by GEE-PBSC method alone; (5) bare land is badly mixed with other land, and the spatial consistency is the worst.

\section{CONCLUSTION}

Using GEE-PBSC method, we classify Landsat 5 TM imageries in Shandong in 2010, and compare our classified product with GlobeLand30-2010 to analyses the accuracy of GEE-PBSC method. The GEE-PBSC method can achieve a 
higher test accuracy and our product can maintain a high spatial consistency with GlobeLand30, but there is still a big gap between them. In our classification, we only used the pixel information of the imageries, and the index-based classification method and other auxiliary data are not adopted. As a result, some land cover types with similar pixel information are difficult to be classified by GEE-PBSC method or the purity of classification results is not high enough. In addition, the GEE-PBSC's ability to classify artificial land surface and cropland deserves attention, which can provide a preliminary and reliable result for higher accuracy land cover mapping.

\section{REFERENCES}

Breiman, L., 2001. Random forests. Machine learning, 45(1), pp.5-32.

Coppin, P.R. and Bauer, M.E., 1996. Digital change detection in forest ecosystems with remote sensing imagery. Remote sensing reviews, 13(3-4), 207-234.

Drusch, M., Del Bello, U., Carlier, S., Colin, O., Fernandez, V., Gascon, F., Hoersch, B., Isola, C., Laberinti, P., Martimort, P. and Meygret, A., 2012. Sentinel-2: ESA's optical high-resolution mission for GMES operational services. Remote sensing of Environment, 120, 25-36.

Feddema, J.J., Oleson, K.W., Bonan, G.B., Mearns, L.O., Buja, L.E., Meehl, G.A. and Washington, W.M., 2005. The importance of land-cover change in simulating future climates. Science, 310(5754), 1674-1678.

Foley, J.A., DeFries, R., Asner, G.P., Barford, C., Bonan, G., Carpenter, S.R., Chapin, F.S., Coe, M.T., Daily, G.C., Gibbs, H.K. and Helkowski, J.H., 2005. Global consequences of land use. science, 309(5734), 570-574.

Giri, C., Pengra, B., Long, J. and Loveland, T.R., 2013. Next generation of global land cover characterization, mapping, and monitoring. International Journal of Applied Earth Observation and Geoinformation, 25, 30-37.

Goldblatt, R., Rivera Ballesteros, A. and Burney, J., 2017. High spatial resolution visual band imagery outperforms medium resolution spectral imagery for ecosystem assessment in the semi-arid brazilian sertão. Remote Sensing, 9(12), 1336.

Gorelick, N., Hancher, M., Dixon, M., Ilyushchenko, S., Thau, D. and Moore, R., 2017. Google Earth Engine: Planetary-scale geospatial analysis for everyone. Remote Sensing of Environment, 202, 18-27.

He, M., Kimball, J., Maneta, M., Maxwell, B., Moreno, A., Beguería, S. and Wu, X., 2018. Regional crop gross primary productivity and yield estimation using fused landsat-MODIS data. Remote Sensing, 10(3), 372.

Lee, J., Cardille, J. and Coe, M., 2018. BULC-U: Sharpening Resolution and Improving Accuracy of Land-Use/Land-Cover Classifications in Google Earth Engine. Remote Sensing, 10(9), 1455.

Li, J. and Roy, D., 2017. A global analysis of Sentinel-2A, Sentinel-2B and Landsat-8 data revisit intervals and implications for terrestrial monitoring. Remote Sensing, 9(9), 902.

Liu, C.C., Shieh, M.C., Ke, M.S. and Wang, K.H., 2018. Flood prevention and emergency response system powered by Google Earth Engine. Remote Sensing, 10(8), 1283.

Mahdianpari, M., Salehi, B., Mohammadimanesh, F., Homayouni, S. and Gill, E., 2019. The first wetland inventory map of newfoundland at a spatial resolution of $10 \mathrm{~m}$ using sentinel-1 and sentinel-2 data on the google earth engine cloud computing platform. Remote Sensing, 11(1), 43.

Naidoo, R., Balmford, A., Costanza, R., Fisher, B., Green, R.E., Lehner, B., Malcolm, T.R. and Ricketts, T.H., 2008. Global mapping of ecosystem services and conservation priorities. Proceedings of the National Academy of Sciences, 105(28), 9495-9500.

Pereira, H.M., Ferrier, S., Walters, M., Geller, G.N., Jongman, R.H.G., Scholes, R.J., Bruford, M.W., Brummitt, N., Butchart, S.H.M., Cardoso, A.C. and Coops, N.C., 2013. Essential biodiversity variables. Science, 339(6117), 277-278.

Reid, W.V., Chen, D., Goldfarb, L., Hackmann, H., Lee, Y.T., Mokhele, K., Ostrom, E., Raivio, K., Rockström, J., 
Schellnhuber, H.J. and Whyte, A., 2010. Earth system science for global sustainability: grand challenges. Science, 330(6006), 916-917.

Robinson, N., Allred, B., Jones, M., Moreno, A., Kimball, J., Naugle, D., Erickson, T. and Richardson, A., 2017. A dynamic Landsat derived normalized difference vegetation index (NDVI) product for the conterminous United States. Remote Sensing, $9(8), 863$.

Sidhu, N., Pebesma, E. and Câmara, G., 2018. Using Google Earth Engine to detect land cover change: Singapore as a use case. European Journal of Remote Sensing, 51(1), 486-500.

Sproles, E., Crumley, R., Nolin, A., Mar, E. and Lopez Moreno, J., 2018. SnowCloudHydro-A New Framework for Forecasting Streamflow in Snowy, Data-Scarce Regions. Remote Sensing, 10(8), 1276.

Stocker, T. ed., 2014. Climate change 2013: the physical science basis: Working Group I contribution to the Fifth assessment report of the Intergovernmental Panel on Climate Change. Cambridge University Press.

Tsai, Y., Stow, D., Chen, H., Lewison, R., An, L. and Shi, L., 2018. Mapping vegetation and land use types in fanjingshan national nature reserve using Google Earth Engine. Remote Sensing, 10(6), 927.

Turner, B.L., Moss, R.H. and Skole, D.L., 1993. Relating land use and global land-cover change: a proposal for an IGBP-HDP core project. A report from the IGBP/HDP Working Group on Land-Use/Land-Cover Change. Global Change Report (Sweden).

Verbesselt, J., Zeileis, A. and Herold, M., 2012. Near real-time disturbance detection using satellite image time series. Remote Sensing of Environment, 123, 98-108.

Weng, Q., Liu, H. and Lu, D., 2007. Assessing the effects of land use and land cover patterns on thermal conditions using landscape metrics in city of Indianapolis, United States. Urban ecosystems, 10(2), 203-219.

Woodcock, C.E., Allen, R., Anderson, M., Belward, A.,
Bindschadler, R., Cohen, W., Gao, F., Goward, S.N., Helder, D., Helmer, E. and Nemani, R., 2008. Free access to Landsat imagery. Science, 320(5879), 1011-1011.

Wulder, M.A., Coops, N.C., Roy, D.P., White, J.C. and Hermosilla, T., 2018. Land cover 2.0. International Journal of Remote Sensing, 39(12), 4254-4284.

Wulder, M.A., Masek, J.G., Cohen, W.B., Loveland, T.R. and Woodcock, C.E., 2012. Opening the archive: How free data has enabled the science and monitoring promise of Landsat. Remote Sensing of Environment, 122, 2-10.

Xian, G., Crane, M., 2006. An analysis of urban thermal characteristics and associated land cover in Tampa Bay and Las Vegas using Landsat satellite data. Remote Sensing of environment, 104(2), 147-156.

Xiong, J., Thenkabail, P., Tilton, J., Gumma, M., Teluguntla, P., Oliphant, A., Congalton, R., Yadav, K. and Gorelick, N., 2017. Nominal 30-m cropland extent map of continental Africa by integrating pixel-based and object-based algorithms using Sentinel-2 and Landsat- 8 data on Google Earth Engine. Remote Sensing, 9(10), 1065.

Yüksel, A., Akay, A. and Gundogan, R., 2008. Using ASTER imagery in land use/cover classification of eastern Mediterranean landscapes according to CORINE land cover project. Sensors, 8(2), 1237-1251.

Zell, E., Huff, A.K., Carpenter, A.T. and Friedl, L.A., 2012. A user-driven approach to determining critical earth observation priorities for societal benefit. IEEE Journal of Selected Topics in Applied Earth Observations and Remote Sensing, 5(6), 1594-1602.

Zhu, Z., 2017. Change detection using landsat time series: A review of frequencies, preprocessing, algorithms, and applications. ISPRS Journal of Photogrammetry and Remote Sensing, 130, 370-384. 